\title{
Macro-Systems Role of Marketing: Do We Trade Environment for Welfare?
}

\section{Djavlonbek Kadirov'}

\begin{abstract}
The purpose of this research is to advance understanding of the macro-systems role of marketing. The author augments the equivocal principle of marketing (EPM) with the hypothesis that marketing has a negative indirect impact on societal welfare. The estimation of a structural error correction model in the context of the U.S. marketing system confirms that there exists a negative long-run relationship between environmental entropy and sustainable welfare with marketing positively associated with environmental entropy. This fact invalidates the assumptions behind the trade-off conjecture, which could only be supported if one is willing to accept the economic welfare myth.
\end{abstract}

\section{Keywords}

macromarketing, macro-systems impact, trade-off conjecture, societal welfare, economic welfare, sustainable welfare, environmental entropy, time-series modeling, long-run and short-run impacts, structural error correction model

\begin{abstract}
They picnic on exquisitely packaged food from a portable icebox by a polluted stream and go on to spend the night at a park which is a menace to public health and morals. Just before dozing off on an air mattress, beneath a nylon tent, amid the stench of decaying refuse, they may reflect vaguely on the curious unevenness of their blessings. Is this, indeed, the American genius?
\end{abstract}

John Galbraith $(1958,203-204)$

The impact of marketing on the macro-systems of society and the natural environment lies at the heart of macromarketing (Crane 2000; Hunt 1981; Kilbourne and Beckmann 1998; Kilbourne, McDonagh, and Prothero 1997; Reidenbach and Oliva 1983; Sheth and Sisodia 2005; Varey 2010; Wilkie and Moore 1999). Discussions of this impact often emphasize "the equivocal principle of marketing" (EPM), both explicitly and implicitly (Reidenbach and Oliva 1983, 33). EPM defines the macro-systems role of marketing, positing that the macro impact of marketing is two-pronged. On one hand, marketing creates a number of material and symbolic benefits both for society as a whole and for its individual members (Reidenbach and Oliva 1983; Wilkie and Moore 1999). On the other hand, marketing aggravates environmental degradation by intensifying waste generation, air and noise pollution, and resource depletion (Schor 1999; Dawson 2003; Smith 1998; Durning 1992; Reidenbach and Oliva 1983; Varey 2010). Missing from EPM is the impact of environmental degradation on societal welfare, as implied by the opening quotation by Galbraith (1958). How does environmental degradation influence societal welfare? What does this relation imply for the macrosystems role of marketing?
Interestingly, advocates of micro-managerial marketing do not deny assumptions behind EPM but, rather, adapt it to support their story about the macro role of marketing. From their perspective, the orthodox conception of marketing holds the high ground amid the claims of moral neutralitymarketing is simply the (good) science of creating satisfaction, which translates existing, immediate demand into product assortments - while negative consequences are attributed to consumer choice (Crane and Desmond 2002). Moreover, even if advocates of micro-managerial marketing acknowledge a negative impact on the environment, they rate the impact as less important than the primary goal of consumer happiness. Hence, environmental degradation is an externality, spillover, or side effect of the "ultimate noble quest" for the wellbeing of humanity. Entropy is simply a necessary sacrifice or price (the significance of which is still open to debate) to be paid to attain societal progress. This point of view implies a positive relationship between environmental degradation and societal welfare: an unavoidable increase in environmental degradation is believed to return a significant gain in societal welfare in the long term. Herein, this is called the trade-off conjecture. According to trade-off conjecture, citizens trade

\footnotetext{
'School of Business, Eastern Institute of Technology, Napier, New Zealand

\section{Corresponding Author:}

Djavlonbek Kadirov, School of Business, Faculty of Applied Science, Business and Computing, Eastern Institute of Technology, Private Bag I20I, Hawke's Bay Mail Centre, Napier 4I42, New Zealand Email: dkadirov@eit.ac.nz
} 
some of their natural environment for a better life, and the trade is worth the cost. In contrast, a growing number of conceptual and empirical studies have indicated that societal well-being is positively associated with environmental quality (Ferrer-i-Carbonell and Gowdy 2007; Gowdy 2005; Galbraith 1958; Varey 2010; Welsch 2002, 2006). These studies challenge trade-off conjecture by insisting that environmental degradation will eventually downgrade societal welfare. This is called an indirect effect of marketing. In other words, expanding marketing systems intensify environmental degradation, which, in turn, negatively affects societal welfare.

Realizing that both aforementioned conjectures represent a unique story about the macro role of marketing, a dilemma arises regarding which one to accept as a basis for decisions in business and public domains. A resolution to the debate between the trade-off conjecture and the indirect effect requires a macro-perspective. Differing from a micro-approach, a macro-perspective involves not only the analysis of the concepts at the level of higher aggregation but also the scrutiny of assumptions and values that underlie these concepts. Moreover, a longitudinal study that separates long-run effects from short-run ones is necessary. The long-run effect refers to a cumulative impact, whereas the short-run effect refers to a contemporaneous influence of one factor on another. For example, the long-run effect indicates the impact on societal welfare of a one-time change in environmental degradation that has accumulated over several decades. The short-run effect refers to a contemporaneous (one-off) change in societal welfare due to a one-time change in the level of environmental entropy. Basing inferences on only short-run effect estimates might greatly bias conclusions. For instance, a disproportionate jump in the production and purchase of goods may increase welfare for both consumers and producers in the short term (i.e., 1-2 years), whereas the effect on welfare of this event in the long run (i.e., several decades) might remain a mystery.

Currently, there exists a paucity of research on the long-run link between environmental entropy and societal welfare. Understanding this process is important because it directly bears on how marketing should be reformed (Sheth and Sisodia 2006). Is reformism, the incremental improvement of marketing's eco-efficiency, sufficient (Crane 2000; Varey 2010)? Reformism is based on an assumption that a progressively diminishing amount of an increase in environmental degradation is traded for a constant increase in the welfare of citizens in the long run. Alternatively, is there a need for revolutionary transformation, welfare marketing (Varey 2010), which does not compromise with aggression toward the environment: any increase in environmental degradation leads to a significant decrease in societal welfare in the long term. From the public policy point of view, in the case of an established harm to the environment and locality, should the state stipulate compensation payments or full restoration as a remedy (Brown and Gregory 1999)? If the trade-off conjecture is accepted, then the policy inclination will be toward monetary compensation because a harmful practice would be deemed "necessary" in terms of welfare-for-all, where compensation would restore local welfare. Moreover, there will be less motivation to enforce mechanisms other than financial penalties to stop similar ecologically harmful practices in the future.

Hence, the purpose of this investigation is to explore the extent to which environmental degradation impacts societal welfare in the context of the EPM theory. To this end, two concepts of societal welfare are differentiated: economic welfare and sustainable welfare. It is argued that the association between environmental entropy and societal welfare is positive if societal welfare is conceptualized as economic welfare. The association is negative when societal welfare is conceptualized as sustainable welfare. Then, a conceptual framework is developed that captures both long- and short-run relationships between the scale of a marketing system, environmental entropy, and societal welfare. Next, the hypotheses are tested empirically by developing and estimating a structural error-correction model in the context of the U.S. economy. Environmental degradation is found to be positively related to economic welfare and negatively related to sustainable welfare in the long run. The model indicates that short-run dynamics are complex. It finds that long-run dynamics significantly influence the short-run relationship between environmental entropy and societal welfare. In essence, the upshot of the argument is that understanding the macro role of marketing greatly depends on how one conceptualizes societal welfare.

Next, the main concepts that comprise EPM are explained, in particular, the two different concepts of societal welfare and assumptions that underlie these concepts.

\section{EPM Concepts}

\section{Marketing System}

In contrast to the dominant characterization of marketing as the function of an organization (Mittelstaedt, Kilbourne, and Mittelstaedt 2006), the emphasis of EPM is broad - marketing activities organized as "the provisioning system of society" (Dowling 1983; Fisk 1974). Macromarketing mainly deals with the impact of the marketing system on society (Hunt 1981). Specifically, the marketing system is defined as the embodiment of social mechanisms of life support and provisioning (Bartels 1970). Another definition states that the marketing system is "a network of individuals, groups, and/or entities linked directly or indirectly through sequential or shared participation in economic exchange that creates, assembles, transforms, and makes available assortments of products, both tangible and intangible, provided in response to customer demand" (Layton, 2007, 230). Of interest to this investigation are the scale and scope of the marketing system and how it evolves over time. Considering that both the supply-side and demand-side of the system are relevant (Kotler and Levy 1973), it is assumed that producer marketing activities and consumption practices represent the marketing system as the two sides of a coin. A change (increase or decrease) in the scope of the marketing system implies growth and decline in either producer marketing activities or consumption expenditure. 


\section{Environmental Entropy}

Environmental entropy refers to the extent to which environmental pollution causes degradation over time. Borrowed from thermodynamics, entropy means "a state of disorder" (Reidenbach and Oliva 1983). In other words, the natural environment is the ecosystem in perfect order, while an increase in entropy means an increasing magnitude of disorder. Currently, strong scientific evidence indicates that significant disorder (i.e., entropy) in the Earth's biosphere is induced by human economic activities (Stern 2007). Moreover, the evidence suggests that a major factor fostering entropy is the release of greenhouse gases (Stern 2007).

\section{Societal Welfare}

Generally, societal welfare refers to the aggregate measure of well-being and happiness of the members of society evolving over time. Nath (1973) called for the analysis of implicit value judgments behind the different theories of societal welfare. He refers to Keynes, who emphasized an examination of the underlying principles of neoclassical economics, an approach that was,

\footnotetext{
... not so much in finding logical flaws in its [the neoclassical theory of economics] analysis as in pointing out that its tacit assumptions are seldom or never satisfied, with the result that it cannot solve the economic problems of the actual world" (quoted in Nath 1973, 66).
}

Examining dominant value and belief structures that are prevalent in a particular society is at the heart of macroanalysis (Kilbourne, McDonagh, and Prothero 1997). This article adopts a similar approach and examines major assumptions, principles, and value judgments that underlie the different conceptualizations of the welfare of society. It distinguishes two conceptualizations of welfare. The economic welfare myth is based on the overarching assumption that an increase in consumption or income is sufficient evidence for an improvement in general welfare. The sustainable welfare perspective is built upon the principle that contemporary production and consumption practices should not undermine the prospects of similar practices for future generations.

Economic welfare. From an economic perspective, the concept of welfare has two major philosophical foundations, namely, Paretian and Pigouvian (Nath 1973). The Paretian concept of welfare is based on two primary assumptions. First, it is believed that the methods for deriving welfare are incomparable between individuals because every individual is his or her own judge of what is best for him or her. Second, if at least one person's welfare increases while everybody else's stays constant, the welfare of society increases. The Paretian welfare assumptions form the backbone of neoclassical economics. Critics have shown that the first assumption fails to recognize that individual market players could make incorrect judgments about own long-term welfare-specifically when collective welfare is at stake (Crane and Desmond, 2002; Shultz and Holbrook 1999). The second assumption became a justification for economic growth while more and more economic policies were formulated to add to the personal fortunes of the rich while stabilizing the income of the poor (Nath 1973). In contrast, Pigou (2002) claimed that the welfare judgments of individuals are similar and that an extra dollar received (or consumed) by a poor person creates a larger magnitude of welfare in comparison to an extra dollar received by the rich. Although, Pigovian assumptions are favored over Paretian ones by some welfare economists, these assumptions by no means represent a radical shift in ethical judgment about societal welfare. In his analysis of these two philosophical foundations, Nath (1973, 14) showed that both approaches represent value judgments rather than being "more or less ethics-free" evaluations. In fact, these two philosophical foundations are micro in essence because they share the following assumptions: (1) welfare is derived from income, leisure, and wealth, hence, consumption (as a method of deriving utility) is a route to happiness and (2) individual utilities (welfares) add up to societal welfare. These assumptions are part of the system of beliefs of an industrialized Western society, called the dominant social paradigm (DSP) and analyzed in depth by Kilbourne, McDonagh, and Prothero (1997). From the macro perspective, one realizes that both Paretian and Pigovian perspectives are essentially product of the same dominant way of thinking about welfare in Western economies. Accordingly, both perspectives would agree that growth over time, even if it is incremental, be it in the levels of gross domestic product (GDP), consumption, or national income, would lead to increase in societal welfare. The disagreement between the Paretian and Pigovian perspectives is simply a matter of magnitude.

The neoclassical thinkers propagated a tale of a free market in which economic agents maximize general welfare by pursuing self-interests (Davies 2004). By maximized welfare, neoclassical economists meant a sum of all utilities derived through consumption. Accordingly, welfare means consumption, and consumption means welfare. More formally, this view means that consumption aggregated across individuals is the best measure of societal welfare, while an increase in societal welfare largely comes from increase in aggregate consumption. The proxy measure of consumption and income, GDP, is ubiquitously quoted by commentators, politicians, and popular media to mean societal welfare, although prominent economists have long argued to the contrary (Kuznets 1934; Talberth and Bohara 2006; Stockhammer et al. 1997; Talberth, Cobb, and Slattery 2007). Kilbourne, McDonagh, and Prothero $(1997,4)$ argued that "the sure and only road to happiness is through consumption" is deeply ingrained in and promoted by behaviors, values, and assumptions institutionalized in the political, sociocultural, economic, and technological spheres of society (i.e., DSP). Scitovsky (1976) argued that the economic welfare assumption was not only ideological but also instrumental - he observed that even though many realize that the sources of human happiness are multiple, complex, and intertwined, societal institutions facing complex decisions find 
it more convenient to make decisions based on the reduced concept of welfare. Furthermore, exploring potential reasons for misguided assumptions about the sources of happiness, Scitovsky $(1976,140)$ presented the classical economics theory of "net benefit." The net benefit theory postulates that the existence of income (and accompanied consumption) that pertains to a particular economic agent attests to the existence of a net gain retrieved from economic transactions. Economic transactions are only accomplished if benefits exceed costs. For instance, a person will accept going through the pain of labor to earn $\$ 1000$ only if he or she considers this pain to be less in value than $\$ 1000$. Similarly, a person who consumes the output of this labor (worth $\$ 1000$ ) will only pay for it if he or she expects to gain satisfaction exceeding $\$ 1000$ in value. That is how the existence of $\$ 1000$ in income would indicate the existence of larger benefits shared between a laborer and a consumer. Scitovsky questioned "a big logical step" made by economists in assuming that the measure of an aggregate income (consumption) simply stands for the aggregation of all net gains retrieved by both income earners and consumers. Specifically, the net benefit postulate ignores interactivity between economic agents - the process of net gain retrieval may create costs (negative externalities) for other agents, and also, the benefit creation process could undermine the possibility of creating similar benefits in the future. In summary, Scitovsky (1976) showed that the direct sum of individual gains (micro-perspective) does not equal societal welfare at the macro level. Moreover, he argued that societal welfare (human happiness) has many sources, and economic welfare (i.e., happiness generated by income or consumption) is only one of these sources.

Ahuvia and Friedman (1998) investigated three reasons for equating happiness with economic well-being (i.e., income): the comparative, goal-attainment, and hedonic perspectives. More income or wealth generates more satisfaction with life because one will be (1) better-off than someone else or compared to a certain material standard according to the comparative perspective; (2) closer to his or her life goals according to the goal attainment perspective; and (3) able to pursue selfgratifying activities to a greater extent from the hedonic perspective. Yet again, a big logical step might be implicitsocietal welfare as a macro concept is not the aggregation of individual well-being, which is a micro construct. A proper macro question, such as "will raising the incomes of all increase the happiness of all," is a more complex and involved matter (Easterlin 1995, 35).

Arguably, this issue is not so much about the absolute magnitude of income, consumption, or economic welfare, but how changes in these measures are understood or explained. The economic welfare perspective is based on a myth perpetuated and supported by societal institutions that an increase in income (consumption) means an increase in societal welfare. This myth, accompanied by mottos such as "economic growth is good," is scientifically rationalized (Scitovsky 1976), institutionalized (Kilbourne, McDonagh, and Prothero 1997), and popularized (Varey 2010). The myth is so ubiquitous that every significant increase in either GDP or income or consumption is met with public cheer reminiscent of cultural or educational populism at its best (Holbrook 1998).

Sustainable welfare. Raw economic measures (e.g., national income, GDP, and consumption) do not appropriately represent welfare because they must be corrected for a number of factors that generally cause fluctuations in welfare (Talberth, Cobb, and Slattery 2007). The economic welfare myth largely ignores the negative effects of economic progress for the general well-being of the population. Such negative effects range from depletion of natural capital to environmental degradation and toxic pollution to social unrest and crime to income inequality and unemployment. From a technical perspective, a registered growth in income or consumption does not always spring from welfare enhancing activities. Income increases can also come from welfare neutral or welfare reducing activities, such as pollution abatement costs; crime related costs; and toxic material production, use, and disposal (Talberth and Bohara 2006; Stockhammer et al. 1997; Talberth, Cobb, and Slattery 2007).

The sustainable welfare perspective stems from similar concerns about economic welfare, and efforts directed at rectifying those concerns, as well as an alternative conceptual foundation, in particular the conceptualization of income, consumption, and capital suggested by Hicks and Fisher (see Lawn 2003 for in-depth discussion). Hicks (1975) defined personal income as the maximum amount a person could consume without undermining his or her capacity to consume in subsequent years. Taking the macro perspective, national income is the amount of products and services that can be produced and consumed without compromising the capacity to produce and consume the same amount in the future. It is clear from his definition that Hicks saw no other way to define (national) income and, thus, economic welfare than from the sustainability perspective, which suggests that sustainability was a fundamental component of classic economic thought rather than being a marginalized perspective. From a practical perspective, a particular range of comfort-generating (Scitovsky 1976) consumption expenditures should not be counted as the part of national income. These expenditures include the cost of replacing production and consumer goods, for instance, consumer durables replaced because of engineered/built-in obsolescence or accelerated fad/style cycles; the cost of abating the side-effects of consumerist lifestyle and other economic activities (i.e., household pollution, vehicle accidents, family breakdown, and health problems); and the cost of the permanently lost natural capital (i.e., resource depletion, air-water pollution, and damaged ecosystems). Moreover, the Hicksian perspective exposes the "consumption increase = welfare increase" myth by demonstrating that a significant part of an increase in consumption might represent the cost of removing "dis-welfare," which adds nothing to welfare (Scitovsky calls this phenomenon "comfort"), meaning that these costs are borne to maintain the required throughput of products and services. Nevertheless, Hicks's definition does not go as far as Fisher's definition of income and capital. Fisher (1906) 
defined national income as the sum of services, extracted from the existing stock of human-made and natural capital and consumed by all individuals within a specific period of time. The same capital may also generate disservices, for example, pollution, noise, social problems, and addiction. Subtracting disservices from services would indicate an accurate level of welfare. In essence, Fisher made a distinction between capital and income. According to Fisher, goods produced and purchased (registered as consumption expenditure in national accounts) in a particular year, even a mundane product, such as a loaf of bread, contributes to capital, whereas the enjoyment of that capital depends on individual behavior and represents income (e.g., durables might not be used up entirely in a particular year or perishables can be wasted). Lawn (2003) noted,

\footnotetext{
... the Fisherian view of income is superior in that the former [the Hicksian definition] wrongly associates economic welfare with the rate of [sustainable] production and consumption. The Fisherian perspective is different in that it takes the view that economic welfare depends on the psychic enjoyment of life .. while it is true that the psychic enjoyment of life cannot be experienced without the existence of physical goods, it is certainly not determined by the rate at which goods are produced and consumed. (p. 111)
}

Another implication of Fisher's perspective is that it gives a completely different perspective on both the uncorrected index of economic welfare (i.e., consumption and GDP) and the corrected one (i.e., sustainable consumption or GDP calculated, using Hicks's definition). Human-made capital constantly depreciates. Hence, the inflow of goods and services represent efforts to maintain the requisite level of capital to ensure a similar output of psychic enjoyment on a year-to-year basis. Moreover, the maintenance of human-made capital requires that some natural capital be sacrificed as low entropy energy-matter turns into high entropy energy-matter (Georgescu-Roegen 1971; Kilbourne, McDonagh, and Prothero 1997). The Hicksian approach corrects the measure of consumption by removing the cost of the depleted natural capital. From Fisher's perspective, the uncorrected (the common approach) and corrected (Hicksian approach) perspectives simply account for the raw cost and sustainable cost, respectively, that will be borne to maintain the same psychic income. Hence, the instance of production and consumption of goods should be interpreted as the cost of welfare, that is, the "necessary evil," rather than welfare per se, even if one is willing to accept the economic welfare model. The cost is to be minimized from the efficiency point of view, so Fisher's (1906) re-interpretation helps one realize that consumption (and production) as an index of cost (but not welfare) must be reduced or kept constant while improving the capital's qualitative capacity to generate welfare. In other words, GDP is to be minimized!

Several indices have been calculated to operationalize sustainable welfare. A popular approach was to adjust GDP to the extent that it echoes the development of sustainable economic welfare over time. Hicks's perspective inspired the
Sustainable Net Domestic Product (SNDP) index, which is calculated by subtracting the depreciation of human capital, the depletion of natural capital, and the sum of defensive and rehabilitative expenditures (the costs of defending citizens from the negative spillovers of market systems) from GDP. Economists Daly and Cobb developed the Index of Sustainable Economic Welfare (ISEW; see Stockhammer et al. 1997). ISEW is calculated in three steps. First, the general consumption base that comprises adjusted current public and private consumption is calculated. The second step involves adjustments for defensive costs, the costs that do not directly contribute to welfare but are borne to repair social and ecological damages to welfare and future reduction in welfare due to the long-term effects of current consumption (e.g., the impact of resource depletion). In the third step, income inequality is taken into account and weighed against a preliminary index calculated in the initial two steps. Also, an improved measure for sustainable societal welfare-Genuine Progress Indicator (GPI) - has been proposed. GPI is similar to ISEW but puts more emphasis on society's economic and social progress over time. It takes into account adjusted consumption, income distribution, housework and education, crime, resource depletion, leisure time, defensive costs, public infrastructure, and dependence on foreign assets. Talberth et al. (2007) argued that GPI reflects the sustainable development logic:

... if GPI is stable or increasing in a given year the implication is that stocks of natural and social capital on which all goods and services flows depend will be at least as great for the next generation while if GPI is falling it implies that the economic system is eroding those stocks and limiting the next generation's prospects. (p. 2)

Although the aforementioned indices are suggested as a better replacement for economic welfare, one must realize that these indices are not radical enough to overturn the economic welfare myth, neither do they represent a silver bullet for all problems associated with the economic welfare perspective. In particular, GPI is positioned between the Hicksian and Fisherian perspectives; it cannot fully actualize the ideals of the Fisherian definition due to a number of difficulties in calculation (Lawn 2003). To recapitulate, the sustainable welfare approach based on Hicksian and Fisherian conceptualizations does not completely substitute for the economic welfare myth. However, by exposing illogicalities of neoclassical thinking, the sustainable welfare approach challenges the very foundation of the economic welfare myth.

\section{Long-Run and Short-Run Relationships}

Having distinguished two distinct approaches to conceptualizing welfare, let us now turn to the main question on the nature of a relationship between environmental entropy and societal welfare while accounting for the influence of the scope of marketing activities. Figure 1 exhibits the proposed structure of relationships. The scope for conceptualizing is a historical 


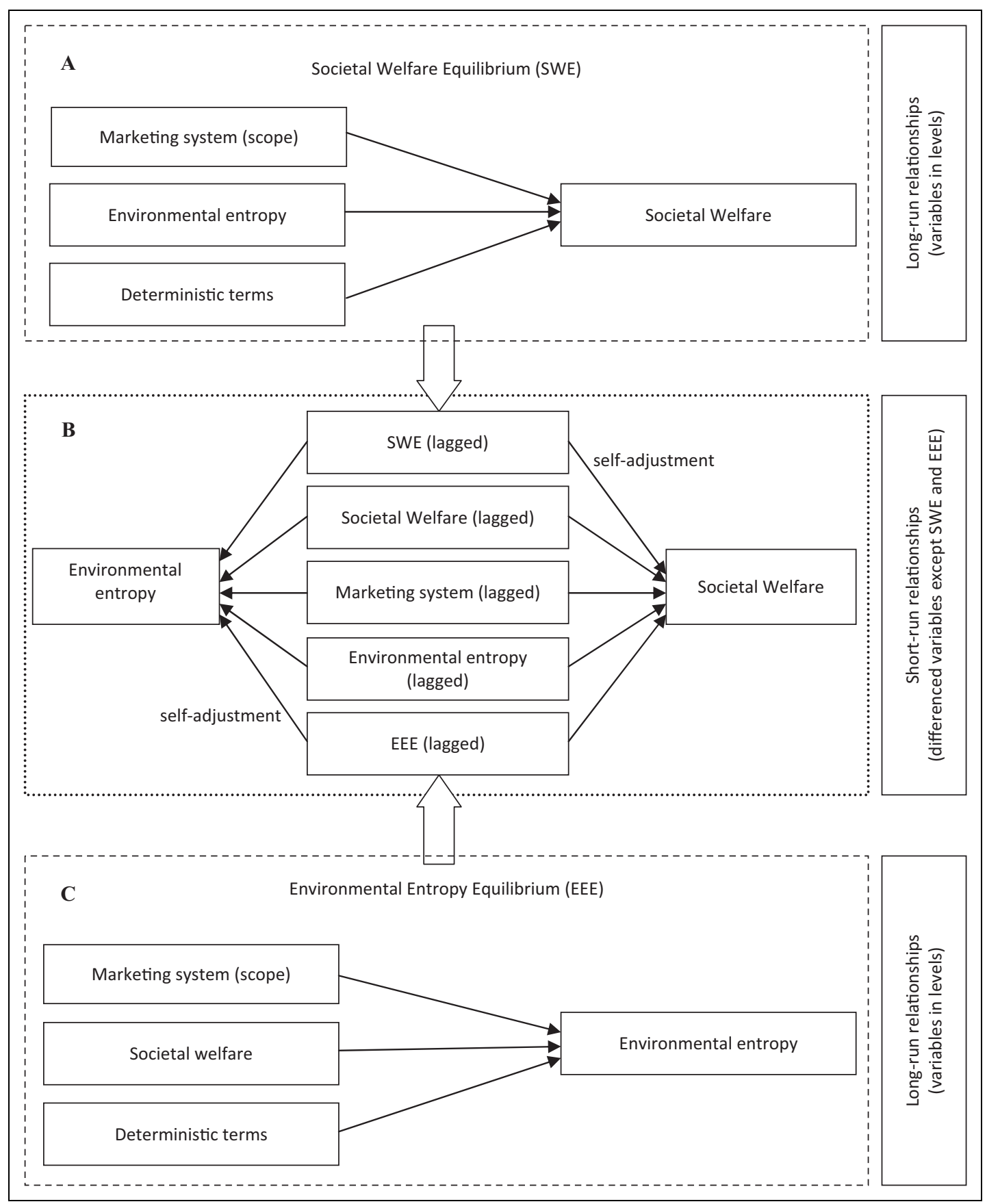

Figure I. Conceptual framework.

(time-series) setting. Consequently, the emphasis is on the disentanglement of long-term relationships (Boxes A and C) from short-term ones (Box B).

The long-run impact refers to the cumulative effect on the dependent variable of a permanent change in the level of an influencing factor, while the short-run impact refers to a contemporaneous change in the dependent variable due to a one-time change in the level of the independent variable. This distinction is very important because policy decisions regarding marketing system regulation can create different short- and long-run dynamics between environmental entropy and societal welfare. For instance, the introduction of a new fossil fuel-based power plant leads to a permanent increase in greenhouse gas emissions. The new plant might have positive effect on welfare in the short run, but its cumulative effect on welfare in the long run might prove to be negative. The use of pesticides and insecticides might also be instrumental in the short term, while creating irreversible effects in the long term. In contrast, pollution mitigation efforts, such as carbon pricing and trading schemes, are likely to have a negative impact on welfare in the short run while substantially improving welfare in the long run. It is important, however, 
to evaluate the long-run impact of a permanent increase in entropy on welfare.

\section{Marketing, Environment and Welfare}

Box A in Figure 1 models long-run relationships that codetermine societal welfare. Although the exact structure of relationships may not be clear at first glance, it is assumed that societal welfare's stochastic evolution is linked to the long-run trends of the marketing system, environmental entropy, and other deterministic terms, such as constants, time trends, and seasonal effects, within a common equilibrium. A possible explanation for such a long-run link is given in the following paragraphs.

Marketing activities framed by DSP and dominated by micromanagerial practices tend to drive society's consumption (Kilbourne, McDonagh, and Prothero 1997; Varey, 2010). Marketing perpetuates the economic welfare myth that more material possessions entail improved happiness and quality of life. What goes unnoticed is that the marketing system as a self-organized live system utilizes the myth to promote its own expansion (Reidenbach and Oliva 1981). The assumption that an increase in income and consumption is the only route to happiness justifies the use of aggressive marketing tactics to accumulate more capital (to make capital owners happier) and the reinterpretation of social issues as marketing problems (to boost consumer happiness; Spring 2003; Varey 2010). Marketing fuels processes such as hyper-commercializationinterpreting an event or relationship through the prism of commercial exchange (De Graaf, Wann, and Naylor, 2005). In health care, researchers have observed medicalization, that is, interpreting various nonmedical human conditions as medical problems and resolving those problems via marketing solutions (Brennan, Eagle, and Rice 2010). The marketing system expands while the economic welfare myth creates the illusion that the expansion increases societal welfare. For instance, Wilkie and Moore (1999) documented a range of welfareincreasing benefits of the aggregate marketing system in the United States.

In essence, the marketing system facilitates the creation of human-made capital at the expense of the natural capital, and during that process, some part of the natural capital is irrecoverably lost (Georgescu-Roegen 1971). Note that human-made capital does not really equal welfare. Here lies the essence of a great trick played by micro-managerial marketing on the views of the populace. The economic welfare myth is propagated ubiquitously, which, in consequence, leads to the widespread misconception that environmental degradation is the necessary price to be paid for societal progress. Hence, one can say that the trade-off conjecture is the consequence of the economic welfare myth being profoundly promoted by orthodox marketing practices. Moreover, environmental degradation is taken to be an externality, side effect, or secondary concern, much less important than the business of welfare creation. That is, marketers (or the marketing system as a whole) are on a "noble quest" to better the human lot, and what is lost is a necessary and well-justified sacrifice that was, perhaps, unavoidable. This idea is implicit in neoclassical conceptualizations (Cleveland and Ruth1997) and mainstream marketing thought (Varey 2010). Macromarketers may also not be immune to the trappings of such an aberration. For instance, Reidenbach and Oliva (1983), exploring the effect of marketing on global life systems, argued that marketing activities improve living standards, which means that they cause negative entropy in terms of welfare, while these practices intensify unsustainable consumption and cause an increase in environmental entropy. In Reidenbach and Oliva's words “... the marketing function, while extending our human existence is reducing the ability of our environment to support our continued existence" (p. 37). This conjecture assumed that environmental quality must inevitably be sacrificed to attain progress in society. Reidenbach and Oliva (1983) envisaged a tradeoff between environmental sustainability and the standards of living - a marginal increase in well-being is attained by giving up some degree of environmental quality and vice versa.

Hypothesis 1: From the economic welfare perspective, a permanent increase in the level of environmental entropy leads to an increase in societal welfare in the long run.

Hypothesis 1 might hold if the expansion of the marketing system is interpreted as an increase in general welfare consistent with the economic welfare myth. However, a growing body of research shows that income or consumption is not the only source of happiness, both at individual and societal levels (Blanchflower and Oswald 2004; Easterlin 1995; Ferrer-i-Carbonell and Gowdy 2007; Galbraith 1958; Varey 2010; Welsch 2002, 2006). Despite a paucity of research in this area, a number of empirical studies have shown that happiness is positively related to the quality of the natural environment, a fact silenced by the economic welfare myth. In a cross-national study involving fifty-four countries, Welsch (2002) found that pollution is negatively correlated with the self-reported measure of individual well-being. In another study involving European countries, Welsch (2006) reported that the intercountry and temporal variation in subjective well-being is negatively associated with the level of pollution, that is, the level of nitrogen dioxide and lead concentration in air. In other words, the lower the level of environmental entropy, the higher the level of subjective well-being. In a similar study based on the British Household Panel Survey data, Ferrer-i-Carbonell and Gowdy (2007) found a strong negative relationship between the perceived level of pollution and subjective well-being. Moreover, the reported concern over the degradation of the ozone layer had a negative effect on well-being. The authors argued that an increasing level of actual pollution intensifies an individual's psychological concern about environmental entropy, which leads to decreased well-being. Also, Rehdanz and Maddison (2005) discovered that climate changes that might occur due to human activity cause a significant effect on well-being. In another study, Rehdanz and Maddison (2008) analyzed the data from a German socioeconomic panel and established a negative relationship between entropy 
Table I. Operationalization

\begin{tabular}{|c|c|c|c|c|}
\hline Concepts & Abbreviation & Unit Of Measurement & Operationalization & Source \\
\hline $\begin{array}{l}\text { The scope of the marketing } \\
\text { system: Personal } \\
\text { Consumption }\end{array}$ & $\begin{array}{l}\text { CON (levels) } \\
\text { con (logs) } \\
\Delta \text { con (differenced) }\end{array}$ & $\begin{array}{l}\text { Constant U.S. } \\
\text { dollars per capita }\end{array}$ & $\begin{array}{l}\text { Real personal consumption } \\
\text { expenditure }\left(\mathrm{CONS}_{t}\right) \text { for the } \\
\text { period 1950-2007 }\end{array}$ & $\begin{array}{l}\text { The Economic Report of the } \\
\text { President }\end{array}$ \\
\hline $\begin{array}{l}\text { Societal welfare: Economic } \\
\text { welfare perspective }\end{array}$ & $\begin{array}{l}\text { EW (levels) } \\
\text { ew (logs) } \\
\Delta \text { ew (differenced) }\end{array}$ & $\begin{array}{l}\text { Constant U.S. dollars } \\
\text { per capita }\end{array}$ & $\begin{array}{l}\text { Real personal consumption } \\
\text { expenditure }\left(\mathrm{CONS}_{t}\right) \text { for the } \\
\text { period 1950-2007 }\end{array}$ & $\begin{array}{l}\text { The Economic Report of the } \\
\text { President }\end{array}$ \\
\hline $\begin{array}{l}\text { Societal welfare: Sustainable } \\
\text { welfare perspective }\end{array}$ & $\begin{array}{l}\text { SW (levels) } \\
\text { sw (logs) } \\
\Delta \text { sw (differenced) }\end{array}$ & $\begin{array}{l}\text { Constant U.S. dollars } \\
\text { per capita }\end{array}$ & $\begin{array}{l}\text { Genuine Progress Indicator } \\
\text { 1950-2004 } \\
\text { Genuine Progress Indicator } \\
2005-2007\end{array}$ & $\begin{array}{l}\text { Redefining Progress (www. } \\
\text { rprogres.org) } \\
\text { Own estimation }\end{array}$ \\
\hline \multirow{2}{*}{ Environmental entropy } & & & $\begin{array}{l}\text { Carbon dioxide }\left(\mathrm{CO}_{2}\right) \text { emissions } \\
\quad \text { 1950-1979 }\end{array}$ & World Resources Institute \\
\hline & & & $\begin{array}{l}\text { Total greenhouse gas emissions } \\
\quad 1950-1979\end{array}$ & Own estimation \\
\hline
\end{tabular}

(measured as the levels of air pollution and local noise) and subjective well-being. The aforementioned studies mostly focused on average subjective well-being, measured at the individual level, while this article focuses on a macro indicator, sustainable welfare. Also, existing studies focus on spatial differences across different countries, while the current study looks at temporal differences within the same country. Notwithstanding these differences, a consistent relationship is expected: environmental entropy is negatively associated with societal welfare.

Hypothesis 2: From the sustainable welfare perspective, an increase in environmental entropy will cause a decrease in societal welfare in the long run.

The stated hypotheses are relevant if the underlying assumption about the role of the marketing system is made explicit. The assumption is that the scope of the marketing system has a long-term impact on environmental entropy. Box $\mathrm{C}$ in Figure 1 models this assumption. It is hypothesized that long-term variation in environmental entropy is determined by the long-term evolution of the marketing system, societal welfare, and other deterministic terms. Based on growing evidence in macromarketing research on the negative association between orthodox marketing practices and environmental quality (see Kilbourne, McDonagh, and Prothero 1997; Reidenbach and Oliva 1983; Varey 2010 for expanded discussion), the following hypothesis is proposed:

Hypothesis 3: The scope of the marketing system is positively associated with environmental entropy.

\section{Short-Run Effects}

Box B in Figure 1 exhibits anticipated short-run relationships between the variables. Differing from the long-run setting, an answer to the question on a short-run relationship between environmental entropy and societal welfare is complex and equivocal. To determine the exact character of the relationship, one needs to take into account not only direct impacts of the marketing system scope and environmental entropy but also the following groups of factors: autoregressive effects and adjustment to long-run dynamics.

Auto-regression refers to the influence of previous levels on a variable's current level. This effect represents inertia, whereby an increase or decrease in societal welfare in the short run might occur as a continuation of its own tendency to evolve.

Adjustment to long-run dynamics refers to the variable's reaction to the long-run combinations among the variables. In general, the long-run relationships given in Boxes $\mathrm{A}$ and $\mathrm{C}$ in Table 1 engender two stable, non-evolving trends. First, societal welfare evolves in specific (possibly nonlinear) proportion to the marketing system and environmental entropy, generating societal welfare equilibrium (SWE). Second, environmental entropy evolves in specific (possibly nonlinear) proportion to the marketing system and societal welfare, giving rise to environmental entropy equilibrium (EEE). Accepting that the previously defined long-run relationships are relevant, that is, they are non-spurious (i.e., not a work of chance), these relationships are expected to co-integrate the structure, which needs to be determined empirically (Patterson 2000). Cointegration happens when volatile stochastic trends observed 
in many macroeconomic and marketing variables combine to generate stationary (i.e., non-evolving) composite variables (Dekimpe and Hanssens 1995). Short-run changes in the variable levels cause deviations from the long-term equilibrium. Disequilibrium is restored by short-run adjustments in the level of the given variables. Self-adjustment refers to the effect on the variable of an observed disequilibrium. For example, societal welfare might respond to changes in SWE, whereas environmental entropy reacts to disequilibrium in EEE. If logs are used, self-adjustment indicates the rate in percentage terms at which the disequilibrium is removed. Adjustment to equilibria refers to the influence of the equilibrium on variables other than the variable that defined (normalized) the equilibrium. The impact of SWE on environmental entropy and the marketing system and the impact of EEE on societal welfare and the marketing system fall into this category.

By removing the effects of autoregression, self-adjustment, and other equilibria adjustments, the true short-run effect on societal welfare of environmental entropy can be calculated. Short-run (i.e., annual) changes in environmental entropy might not be visible or consequential in terms of their oneoff impact on societal welfare. Stern (2007) argued that the impacts of escalating emissions will only be felt in the long run, and the consequences of climate change do not appear tangible in the short run. Furthermore, the long run is characterized by a positive feedback, that is, pollution amplifying entropy by deteriorating the neutralizing potential of nature and intensifying the natural release of gases, such as methane (Stern 2007). Positive feedback effect does not exist in the short run and hence:

Hypothesis 4: In the short run, societal (sustainable) welfare does not react to changes in environmental entropy.

\section{Empirical Study Operationalization and Data}

The context for the current study is the U.S. marketing system. Table 1 presents the operationalization of the concepts under investigation. The collected time-series data are annual, comprising the period from 1950 to 2007. The data are transformed into natural logarithms. The log of a series is expressed in small letters, whereas the levels are given in capital letters.

To operationalize the scope of the U.S. marketing system, two indicators were employed to represent the consumer and producer domains of the system. The consumer dimension of the marketing system is represented by real personal consumption expenditure for the period 1950-2007, which is taken from the Economic Report of the President of the United States. As a proxy for producer marketing activities, the carryover (adstock) transformation of the time series of historical crossmedia advertising expenditures was used. These data were retrieved from the Web site of the Television Bureau of Advertising (www.tvb.org), which cites the Universal McCann advertising reports. Consistent with the theory of advertising carryover (Broadbent 1979), marketing activities in society should be operationalized as a stock variable. Accordingly, the influence of a marketing expenditure carries over to several subsequent years, although the carryover happens at a progressively diminishing rate. It is assumed that the stock decays naturally, and this decay dramatically reduces the stock level unless more marketing expenditures recover the loss and add more gain. The rate of decay is represented as half-life over one year $(\lambda=0.5)$ (Hanssens, Parsons, and Schultz 2001), meaning that, subject to no additional marketing expenditure, the stock decays by half in one year. Societal adstock levels are calculated using the following formula for transformation:

$$
m a_{t}=a_{t}+\lambda a_{t-1}+\lambda^{2} a_{t-2}+\ldots+\lambda^{2} a_{t-n},
$$

where $m a_{t}$-marketing activities (stock); $a$-cross-media advertising expenditure; $\lambda$-rate of decay.

Consistent with the previously discussed concepts of welfare, two indicators to measure societal welfare are proposed. To be consistent with the economic welfare myth, the same series, real personal consumption expenditure, was selected as a proxy for economic welfare. Sustainable welfare is operationalized through the composite index GPI. GPI for 1950-2004 was retrieved from the Web site of the public policy think tank Redefining Progress (www.rprogres.org). Table 2 shows the method for calculating GPI.

The irony is that the starting base for calculating GPI is the same time series of real personal consumption expenditure. Nevertheless, several reasons argue for GPI being both qualitatively and quantitatively different than the measure of aggregate consumption. First, GPI is conceptually consistent with the Hicksian and Fisherian definition of income and capital (Lawn 2003). Accordingly, GPI is an approximately fair index of sustainable welfare, represented by aggregate consumption corrected for social and environmental costs and services rather than being the sum of all consumption, bad or good. Second, weighted personal consumption that takes into account income distribution is the initial base of GPI. Hence, GPI truly represents the Pigouvian perspective to welfare. In contrast to Pareto's assumptions, an increase in personal consumption does not result in an increase in GPI if this increase deteriorates the distribution of income. In this sense, an extra dollar for the rich is worth far less than an extra dollar for the poor. Also, nonlinear transformation (i.e., weighting the time series by the index of income distribution) makes GPI quantitatively different than personal consumption. Finally, a range of corrections for various costs and services transforms GPI into a distinct variable that can enter a model without causing a severe multicollinearity problem with regard to personal consumption expenditure.

The three missing values for GPI for years 2005-2007 are forecasted on the basis of an underlying data generating process (DGP) identified through the Box-Jenkins methodology (Box and Jenkins 1976). DGP is an autoregressive integrated moving average model (ARIMA) $(1,1,1)$, which is estimated by maximum likelihood. The model's goodness of fit was analyzed using several methods. First, the model outperforms other 
Table 2. Calculating Genuine Progress Indicator

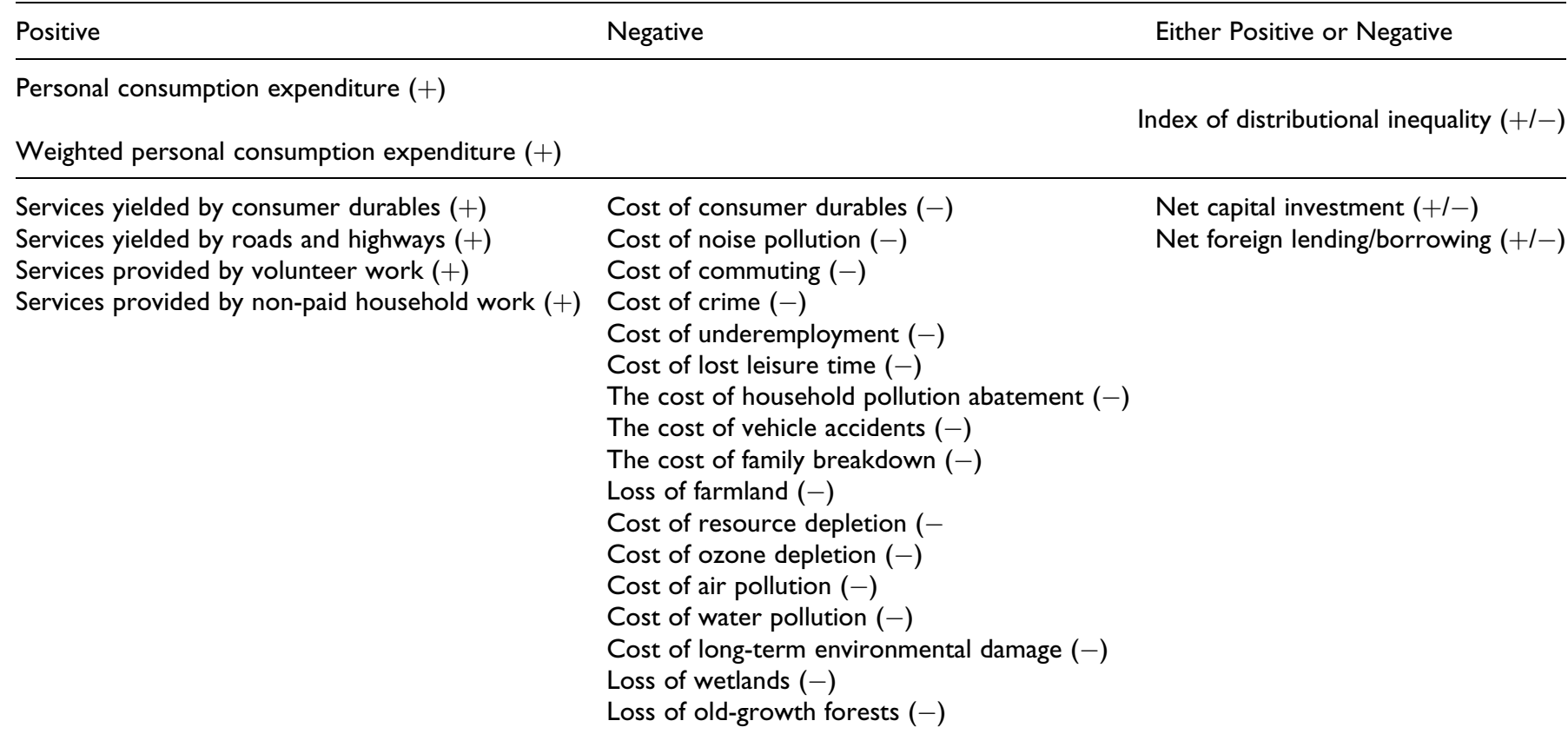

Note: GPI = the sum of all positive and negative items (valued in dollars).

Source: adapted from Lawn 2003.

Table 3. Goodness-of-Fit Statistics for Forecasting Models

\begin{tabular}{|c|c|c|c|c|c|c|}
\hline Series & Model & Deterministic Terms & $\begin{array}{l}\text { Information } \\
\text { Criteria-AIC and SIC }\end{array}$ & Adjusted $R^{2}$ & $\begin{array}{l}\text { Ljung-Box } \\
\text { Tests }\end{array}$ & $\begin{array}{c}\text { F-Test for } \\
\text { DGP Stability }\end{array}$ \\
\hline Methane & $\operatorname{ARMA}(2,0,2)$ & Constant & Minimized & 0.8458 & insignificant & $0.6292, \alpha=.6914$ \\
\hline $\begin{array}{l}\text { Hydrofluocarbons, } \\
\text { perfluorocarbons, } \\
\text { sulfur hexafluoride }\end{array}$ & $\operatorname{ARMA}(I, 0,1)$ & Constant & Minimized & 0.9150 & insignificant & $0.1104, \alpha=.9515$ \\
\hline
\end{tabular}

several alternative models in terms of minimized Akaike Information Criterion (AIC) and Schwartz Bayesian Information Criterion (SIC). Second, the conventional measure of fit is exceptional (adjusted $R^{2}=.99$ ). Third, to test the presence of a systematic movement in the data unaccounted by the model, Ljung-Box tests on the residuals were run. The tests show insignificant autocorrelations and partial autocorrelations, which indicate no unaccounted systematic movement. Finally, the data are split into two equal subsamples and run $F$-test to verify the stability of the derived DGP. The test indicates that DGP is unchanging $(F=0.9536, \alpha=.4301)$.

Greenhouse gas emissions was chosen as a measure for environmental entropy. This measure comprises the emission of six Kyoto greenhouse gases: carbon dioxide, methane, nitrous oxide, hydrofluorocarbons, perfluorocarbons, and sulfur hexafluoride. These emissions are anthropogenic (i.e., they result from human activities). Greenhouse gas emissions have been a major topic of public policy within nation-states and internationally. The $2010 \mathrm{UN}$ summit on climate change in Copenhagen was fully devoted to negotiations regarding emission levels. The data for U.S. greenhouse gas emissions from 1980 to 2007 in million metric tons $\mathrm{CO}_{2}$ equivalent are sourced from the Annual Energy Review 2008 of the Energy Information Administration. For the period 1950-1979, only carbon dioxide $\left(\mathrm{CO}_{2}\right)$ emission is available from the World Resources Institute. For these years, total emission was estimated by backward-forecasting the levels of the other five Kyoto gases emissions and then aggregating them with the available data on $\mathrm{CO}_{2}$ emissions. The goodness-of-fit statistics for the models used for extrapolation are given in Table 3.

\section{Structural Error Correction Model}

The time series of most macroeconomic indices, as well as marketing variables, are likely to be nonstationary (Dekimpe and Hanssens 1995; Patterson 2000). The series are stationary if they evolve about a fixed mean and contain finite variance. Nonstationary (i.e., evolving) series do not revert to a fixed mean; their variance increases with time. Multivariate relationships involving nonstationary time series are likely to be 
spurious (Lutkepohl 1991; Patterson 2000). That is, if nonstationary variables enter a conventional regression analysis, non-accounted stochastic trends might greatly bias estimation results (Patterson 2000).

The common approach was to difference nonstationary variables to reduce them to stationarity and then estimate relationships by a vector autoregressive (VAR) analysis. However, the existence of co-integration is possible, that is, a linear combination among nonstationary variables might prove to be stationary. In this case, differencing all variables creates a misspecification error. In addition, VAR can only provide information on short-run effects. Instead, one can set a structural error correction model (SECM) that allows modeling both long-run and short-run relationships by estimating cointegrating combinations among $k$ number of variables. Using SECM, the analyst does not only derive short- and long-run effects but also the extent to which variables adjust to deviations from long-run equilibrium relationships. The method has been developed extensively and applied in the context of macroeconomic time-series analyses (Johansen 1995; Johansen and Juselius 1990; Patterson 2000).

The starting point for SECM is to define $Y_{t}$ vector in $k$ variables. The basis for SECM is the VAR model of order $\rho$ that involves $k$ variables:

$$
Y_{t}=A_{1} Y_{t-1}+\ldots+A_{\rho} Y_{t-\rho}+\Phi D_{t}+\epsilon_{t}, t=1, \ldots, T,
$$

where $\varepsilon_{1 t}, \ldots, \varepsilon_{k T}$ are iid $N \rho(0, \Omega)$ Gaussian errors and $D_{t}$ is the vector of deterministic terms, such as constants, linear trends, and seasonal dummies.

The VAR model can be reformulated as SECM (Johansen 1995; Lutkepohl 1991):

$\Delta Y_{t}=\Pi Y_{t-1}+\Gamma_{1} \Delta Y_{t-1}+\ldots+\Gamma_{\rho-1} \Delta Y_{t-\rho-1}+\Phi D_{t}+\epsilon_{t}, \quad t=1, \ldots, T$,

where $\Pi=\alpha \beta^{\prime} ; \alpha$-adjustment coefficients; $\beta$-equilibrium (long-run) coefficients; $\Gamma$-matrix of short-run effects.

\section{Formulating Long-Run Equilibria}

The two different conceptions of societal welfare give rise to two possible variations in modeling. In the first case, Hypotheses 2 and 3 encapsulate the assumptions of the economic welfare perspective. Accordingly, two long-run relationships are assumed:

$$
\begin{aligned}
& \mathrm{SW}=\mathrm{MA}^{\beta 11} \mathrm{CON}^{\beta 12} \mathrm{EE}^{\beta 13} \mathrm{C}^{\beta 14}, \\
& \mathrm{EE}=\mathrm{MA}^{\beta 21} \mathrm{CON}^{\beta 22} \mathrm{SW}^{\beta 23} \mathrm{C}^{\beta 24},
\end{aligned}
$$

where, SW-sustainable welfare; MA - producer marketing activities; CON - consumption; EE-environmental entropy; $\mathrm{C}$ - constant or trend.

In essence, these formulas show that SW evolves in nonlinear proportion to producer marketing activities, consumption, and environmental entropy, whereas the stochastic trend of EE links to the trends of marketing, consumption, and sustainable welfare. By taking logarithms (lowercase letters) on both sides of the equation, adding a stochastic term, and simple algebraic manipulation, one arrives at the errorcorrection form that defines the long-run equilibria for sustainable societal welfare (Equation 3) and environmental entropy (Equation 4):

$$
\begin{aligned}
& \mathrm{SWE}=\xi 1=\mathrm{sW}-\left(\beta_{11} m a+\beta_{12} \mathrm{con}+\beta_{13} \mathrm{ee}+\beta_{14} \mathrm{c}\right), \\
& \mathrm{EEE}=\xi 2=\mathrm{ee}-\left(\beta_{21} m a+\beta_{22} \mathrm{con}+\beta_{23} \mathrm{sW}+\beta_{24} \mathrm{c}\right) .
\end{aligned}
$$

The vectors are not identified (i.e., not unique enough) to be susceptible to meaningful interpretation. The two cointegrating vectors can be identified if at least one $(r-1=1)$ unique restriction is imposed on each eigenvector vector. Vector 1 , normalized on $\mathrm{sw}_{t}$, is identified by an exclusion restriction on $m a_{t}\left(\beta_{11}=0\right)$. The rationale for that restriction is based on the conviction that producer marketing activities do not directly influence societal welfare; rather, the impact is indirectly channeled via the short-run effect on consumption and both long- and short-run effects on environmental entropy. In particular, Pan et al. (2007) showed that there is no significant association between the measure of subjective well-being and producer-related marketing variables in the cross-sectional design settings.

For co-integrating Vector 2, which is normalized on ee , macro-system effects of marketing are assumed: the coefficients on $m a_{t}$ and $\operatorname{con}_{t}$ are constrained to be equal $\left(\beta_{21}-\beta_{22}=0\right)$ and the exclusion restriction on $\operatorname{sw}_{t}\left(\beta_{23}=\right.$ $0)$ is imposed. The macro-systems effect of marketing on environmental entropy refers to the fact that producer marketing activities and consumption practices are the two sides of a coin. It is expected that a shock from either $m a_{t}$ or $\operatorname{con}_{t}$ will have a significant effect on environmental entropy. In other words, in the long run, a change in the level of marketing activities while consumption is constant, or a change in consumption while marketing activities are constant, will have an equal impact on environmental entropy. In addition, it should be noted that the last restriction can be relaxed to derive the feedback effect of societal welfare on environmental entropy.

The second possible variation of SECM involves economic welfare $(\mathrm{EW})$, which replaces SW in the model. In short, from the economic welfare perspective, the equilibria will have the following form:

$$
\begin{gathered}
\xi 3=\mathrm{ew}-\left(\beta_{31} m a+\beta_{32} \mathrm{ee}+\beta_{33} c\right), \\
\xi 4=\mathrm{ee}-\left(\beta_{41} m a+\beta_{42} \mathrm{con}+\beta_{43} c\right) .
\end{gathered}
$$

The variable EW replaces SW. CON is removed from Vector 3 because it is equal to EW. The vectors identified by the exclusion restriction on $m a_{t}\left(\beta_{31}=0\right)$ in Vector 3 and the equality restriction $\left(\beta_{41}-\beta_{42}=0\right)$ on Vector 4 . 
Table 4. Results of Unit Root Tests

\begin{tabular}{|c|c|c|c|c|c|c|}
\hline Series & Lags (Information Criteria) & $\operatorname{ADF} \tau_{\tau}($ Trend $)$ & $\operatorname{ADF} Z_{\tau}($ Trend $)$ & Philip-Perron (Trend) & KPSS (Trend) & Unit Root \\
\hline $\operatorname{con}_{t}=\mathrm{ew}_{t}$ & $\left.0(\mathrm{LM}, \mathrm{MAIC})^{\mathrm{a}}\right)$ & $-|.587|$ & -4.9372 & $-|.6306|$ & $0.969^{* * * *}$ & Yes \\
\hline $\mathrm{ee}_{t}$ & 0 (LM,MAIC) & -1.0597 & -2.8255 & -1.08870 & $1.014^{* * * *}$ & Yes \\
\hline Critical value $(\alpha=.05)$ & & -3.45 & -20.7 & -3.488 & 0.146 & \\
\hline
\end{tabular}

Note: a. Modified Akaike Information Criterion.

$* * *$ Significant at $\mathrm{msl}=0.0 \mathrm{l}$.

\section{Model Estimation}

The first step is to verify whether the series are integrated of some order. First, the graphical analysis of the time series is conducted. The individual graphs of the series show a significant time trend in all the series. This means that a trend option of unit root tests is to be employed. Moreover, the autocorrelations of these series show sustained persistence which is the indication of nonstationarity. Different methods are available to test for unit root. Initially, the standard Augmented Dickey-Fuller (ADF) tests for the presence of two unit roots are performed: this hypothesis is rejected for all the series which indicates that less than two unit roots are present in the series. The single unit root is tested by the two standard variations of ADF, $\tau$ and $Z$, the Phillips-Perron test (PP), and KPSS [Kwiatkowski -Phillips -Schmidt -Shin test] (Table 4). ADF's $\tau$ - and $Z$-tests are equivalent but differ in the use of test statistics; they use $t$ - and $Z(\rho)$ variations, respectively (Hamilton 1994). ADF and PP tests differ in terms of treatment of possible serial correlation. To remove serial correlation, ADF augments a hypothesized DGP with more lags of the variable, whereas PP adds a correction factor to a test statistic. For ADF and PP tests, an insignificant statistic (less than a critical value) confirms nonstationarity of order one (i.e., a single unit root). Differing from these, KPSS is a test for stationarity and a significant test statistic indicates the presence of a unit root. A lag structure for the series is determined via minimizing a range of information criteria. For instance, the information criteria AIC, BIC, and HQ (Hannan-Quin) suggest that DGP for $m a_{t}$ can be characterized as containing a single significant lag.

In essence, all calculated tests statistics in Table 4 except PP test for $m a_{t}$ support the hypothesis of a single unit root. Based on these statistics, all of the four series appear nonstationary and integrated of order one. This fact warrants the use of SECM rather than VAR.

The next step is to select a lag length for the model based on several statistics: SIC, HQ, Lagrange Multiplier (LM) tests for no autocorrelation of order 1 and $k$, and Likelihood Ratio (LR) tests for the reduction of lags. For both sustainable welfare and economic welfare variations of SECM, SIC and HQ are minimized at lag 2. Also, LM and LR tests indicate the optimal lag length $2(\alpha=.01)$ for both cases. SECMs are set up as a restricted constant model $\mathrm{H}_{1} *(\mathrm{r})$ that allows co-integration relations to have nonzero intercepts. The results are obtained running Regression Analysis of Time Series (RATS) and Cointegration Analysis of Time Series (CATS) in RATS, version 2 (Dennis et al. 2005).

For sustainable welfare SECM (SWSECM), vector $Y 1_{t}=$ $\left(m a_{t}\right.$ con, $\left.\mathrm{sw}_{t} \mathrm{ee}_{t}\right)$ is defined and estimated by the model. To make sure that the model meets the assumptions of no autocorrelation and normality, an analysis of estimated residuals was performed. LM test for no autocorrelation is satisfactory $\left(\chi^{2}=10.678, \alpha=.829\right)$. The assumption of normality has also been met as the multivariate DoornikHansen test results in $\chi^{2}=10.557, \alpha=.228$. Next, to find out if our assumption of two main co-integrating relationships (long-run equlibria) is valid, rank test statistics are calculated. The rank of $\Pi$ in SECM is equal to the number of co-integrating relations (Patterson 2000). The standard trace test suggests that the hypothesis of all roots are units roots (rank $=0$ ) is not accepted at $\alpha=.000$. Similarly, the hypothesis of rank $=1$ is also rejected $(\alpha=.05)$. The third test $r=2$ is not rejected ( $\alpha=.117$ ), leading to the conclusion that there are two common trends and two co-integrating vectors. The rank for $\Pi=2$ and the two co-integrating vectors are normalized on $\mathrm{sw}_{t}$ and $\mathrm{ee}_{t}$.

In the same vein, vector $Y 2_{t}$ is defined to equal $\left(m a_{t}\right.$ con $=$ $\mathrm{ew}_{t} \mathrm{ee}_{t}$ ) and estimate economic welfare SECM (EWSECM). In the analysis of estimated residuals, LM test indicates no autocorrelation $\left(\chi^{2}=2.046, \alpha=.991\right)$, while the DoornikHansen test confirms normality $\left(\chi^{2}=8.595, \alpha=.198\right)$. Based on the trace test, the hypothesis of rank $=0(\alpha=.000)$ is rejected and rank $=1(\alpha=.157)$ is accepted. Thus, EWSECM has one co-integrating relationship (not two as has been hypothesized).

\section{Findings}

The unrestricted estimates of $\beta_{i}$ coefficients were derived. However, without identifying restrictions, these vectors are not interpretable. Therefore, the restrictions discussed earlier in the section on formulating long-run equilibria were imposed. In SWSECM, the restrictions placed on the vectors are overidentifying $(v=3)$, and the test whether these restrictions are consistent with data is satisfactory, $\chi^{2}(3)=0.063, \alpha=.801$. The restrictions are not binding, which suggests that the model fits the data well. In EWSECM, there is no need for identification because only one co-integrating relationship has 
Table 5. Estimates of Long-Run Equilibrium Effects

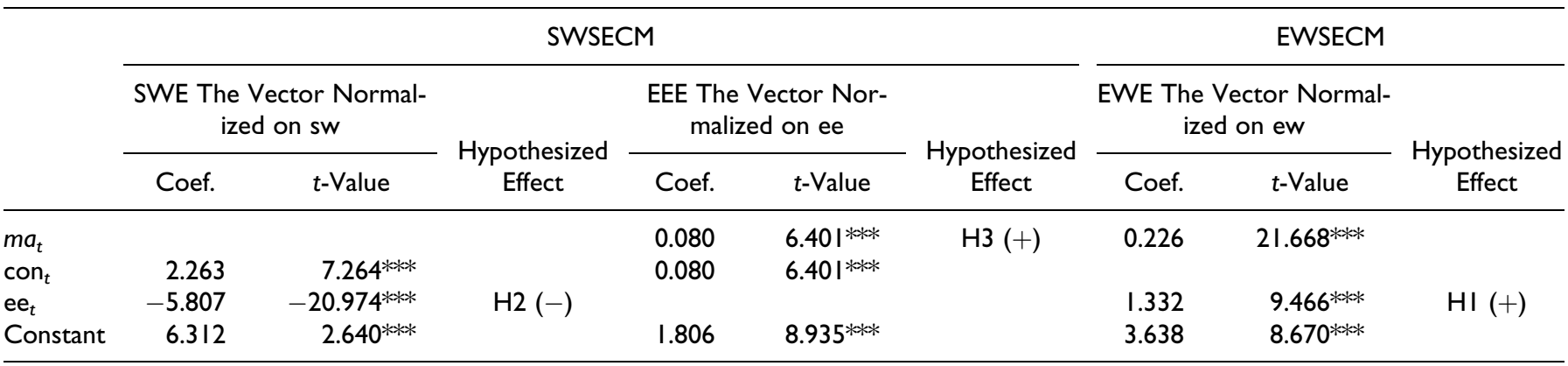

Note: $* * *$ Significant at $\mathrm{msl}=0.01$.

Table 6. Estimates of Short-Run Effects

\begin{tabular}{|c|c|c|c|c|c|c|c|c|}
\hline & \multicolumn{8}{|c|}{ Exogenous Variables } \\
\hline & Coef. & $t$-Value & Coef. & $t$-Value & Coef. & $t$-Value & Coef. & $t$-Value \\
\hline $\mathrm{SWE}_{t-1}$ & -0.092 & $-3.429 * * *$ & -0.056 & $-1.978 *$ & & & & \\
\hline$\Delta m a_{t-1}$ & -0.074 & -1.604 & -0.128 & $-2.629 * *$ & 0.038 & 1.247 & -0.062 & $-1.943^{*}$ \\
\hline$\Delta \operatorname{con}_{t-1}\left(\Delta \mathrm{ew}_{t-1}\right)$ & 0.338 & $2.170 * * *$ & 0.588 & $3.569 * * *$ & 0.590 & $4.217 * * *$ & 0.514 & $3.533 * * *$ \\
\hline$\Delta \mathrm{sw}_{t-1}$ & -0.247 & $-1.717 *$ & -0.145 & -0.955 & & & & \\
\hline$\Delta \mathrm{ee}_{t-1}$ & -0.200 & -1.365 & -0.201 & -1.298 & -0.365 & $-2.588 * *$ & -0.106 & -0.725 \\
\hline
\end{tabular}

Note: $*$ Significant at $\mathrm{msl}=0.10$. $* *$ Significant at $\mathrm{msl}=0.05$. $* * *$ Significant at $\mathrm{msl}=0.0 \mathrm{I}$.

been discovered. The estimated long-run (equilibrium) relationships are given in Table 5.

Because the variables are scaled in natural logarithms, the coefficients represent elasticities (i.e., they show an extent in percentage terms to which a dependent variable reacts to 1 percent change in an independent variable). The analysis confirms that the observed data are consistent with the assumption of two long-run equilibria relationships, as was hypothesized (Hypotheses 1 and 3) from the sustainable welfare perspective. Moreover, the signs of long-run relationships are as expected. For the sustainable welfare perspective, environmental entropy is negatively associated with societal welfare: a 1 percent increase in environmental entropy will eventually result in a 5.8 percent cumulative decrease in societal welfare. The direct effect of consumption on societal welfare is positive. Moreover, from this perspective the underlying assumption holds - the scope of marketing is positively associated with environmental entropy (Hypothesis 3). Thus, the long-run system exposes the twofold effect of the marketing system on societal welfare. On one hand, consumption boosts welfare. On the other hand, the expansion of the whole marketing system leads to an increase in environmental entropy, which, in turn, causes a decrease in societal welfare in the long run. This finding confirms the existence of marketing's indirect effect.
From the economic welfare point of view, the story is different. The use of consumption as a proxy for societal welfare leads one to support Hypothesis 1. Environmental entropy is positively related to societal welfare; in particular, a 1 percent increase in environmental entropy is necessary to attain a 1.33 percent cumulative increase in societal welfare in the long run. In addition, producer marketing activities positively impact $\left(\beta_{41}=0.226, t=21.668\right)$ societal welfare.

Table 6 presents the estimates of the short-run effects for SWSECM and EWSECM. The short-run dynamics are complex, as expected. In SWSECM, the first two columns in Table 6 indicate that societal welfare's autoregressive effect (inertia), self-adjustment, and adjustment to EEE are all significant. The self-adjustment coefficient on SWE is negative ( $\beta=-0.092, t=-3.429)$, which means that 9.2 percent of disequilibrium is removed one period after a shock to the equilibrium. The adjustment rate is not large. For instance, if societal welfare experiences a negative shock $\left(\xi_{1}<0\right)$, then it might take approximately eleven years to restore the original equilibrium. The adjustment to EEE is positive $(\beta=0.578$, $t=3.712$ ), which means that an unexpected shock to the equilibrium causes a short-term increase in societal welfare. Taking into account the aforementioned influence of long-run dynamics, sustainable welfare does not directly respond to 
changes in environmental entropy in the short run $(\beta=-0.200$, $t=-1.365)$, which confirms Hypothesis 4 .

In EWSECM, the short-run effects are given in the four right-hand side columns of Table 6. It can be seen that economic welfare does not adjust to EWE because the coefficient is insignificant $(\beta=-0.042, t=-1.188)$. The autoregressive effect is positive, which indicates the presence of a strong positive inertia: if there was an increase in the last year's economic welfare, then it will increase in the current year too. Most importantly, the controversial result is that an increase in environmental entropy leads to a decrease in economic welfare in the short run $(\beta=-0.365, t=-2.588)$.

\section{Discussion and Implications}

Essentially, EPM is a basis for a narrative that defines the macro-systems role of marketing (Reidenbach and Oliva 1983). EPM declares (1) the positive impact of marketing on societal welfare and (2) the positive association of marketing with environmental entropy. Yet, EPM does not address the relationship between societal welfare and environmental entropy. Instead, the augmented equivocal principle of marketing comprises the third qualifying relationship. The interpretation of the relationship depends on how societal welfare is conceptualized. If the micro-managerial narrative, the economic welfare concept, is accepted, then the relationship is positive, as indicated by the EWSECM model. This leads many to believe that the populace must sacrifice environmental quality to attain progress in welfare, thus confirming the trade-off conjecture (Reidenbach and Oliva 1983). In contrast, SWSECM indicates that the association between environmental entropy and societal welfare proves to be negative if the sustainable welfare perspective is maintained. The negative relation confirms our expectation that an increase in environmental entropy will translate into inferior societal welfare in the long run. Taking into account that the marketing system's scale is positively associated with environmental entropy in the long run, marketing has a negative indirect effect. Hence, marketing simultaneously impacts societal welfare via two paths: direct and indirect. The direct path comprises the significant positive impact on sustainable welfare of consumption. The indirect path involves the influence of the scale of the marketing system on societal welfare through the mediating effect of environmental entropy. Moreover, the equal effect on environmental entropy of marketing activities and consumption shows that the two structural elements of the marketing system are closely intertwined in a macro-systems sense. Thus, the effect is the same whether an impact generates from the marketer or consumer side of the system. Policy makers should realize that environmental programs and mitigation initiatives should not isolate either producers or consumers as the subject of a policy; rather, the programs should address both as a unified system.

The main contribution of this investigation is to further our understanding of the macro-systems role of marketing. This research shows that citizens do (can) not attain superior genuine welfare from simply being content with eco-aggressive marketing practices. The common sentiment that consumers get at least something of value to replace the lost natural environment is a grand illusion fueled by the dominant micromanagerial narrative. The organizational (anthropocentrism) dimension of DSP is related to the trade-off illusion (Kilbourne et al. 2009). The dimension comprises values that put the advancement of humankind before all other considerations. Hence, within DSP, environmental entropy has much less significance than human welfare. The trade-off conjecture should be incorporated into DSP because it represents a macronarrative about marketing, environment, and welfare. It would be interesting to see how a statement "it is alright to sacrifice some of environmental quality for the sake of economic advancement" would fare among other items in the DSP framework.

Spring (2003) identified a consumer as someone who is willing to abandon ethical and moral values in pursuit of material abundance. According to this maxim, that is how the populace assumes the consumer identity. In contrast, the model shows that the consumer is not a person without morals but, rather, one with a false morality. By accepting ecoaggressive and narrow marketing practices, a person might genuinely believe that welfare for all is improving. Hence, the consumer is a citizen who falsely believes that some sacrifices (e.g., environmental quality) are necessary to attain the desired level of advancement. The current study shows, by accepting false morality, people not only lose the precious environment but also give up some of their genuine long-term welfare. In the light of the sustainable welfare concept, one realizes that the situation is not a trade-off at all. Instead, it seems that people are cajoled into giving up environmental quality, as well as their own welfare, in return for the delusion that their wellbeing is improving.

Macromarketers generally assume that the advocates of managerial marketing lack an understanding about the macro-systems role of marketing in society (Mittelstaedt, Kilbourne, and Mittelstaedt 2006). This assumption cannot be further from the truth. The problem is not a matter of a lack of understanding; the problem is the existence of a strong, greatly biased alternative macro narrative. Orthodox marketing practices are morally justified by an implicit story about the macro-role of marketing, underpinned by the economic welfare myth and the trade-off conjecture. These notions are implicit and so ingrained in dominant social practices and institutional values that they have become utterly ubiquitous and, thus, powerful (Kilbourne McDonagh, and Prothero 1997; Varey 2010). Half a century ago, Galbraith (1958) reflected on a similar tendency: could one consider the members of society to be well off when the creation of personal comforts (e.g., product and service assortments) goes hand-in-hand with environmental degradation? Marketing system outputs, such as packaged food, a portable icebox, an air mattress, or a nylon tent, might have been the signs of a luxury life at that time, but these goods cannot foster welfare if there is not an adequate supply of public goods and services (e.g., a sound natural environment and appropriate social infrastructure). Considering that the 
ultimate purpose of the marketing systems is to promote general well-being, marketing must be logically driven to nurture broader natural and social environments as an indispensable element of a market offering.

From a public policy perspective, faith in the trade-off conjecture might have a devastating effect on how environmental regulation is formulated. The trade-off conjecture leads policy makers to believe that established marketing practices are indispensible despite their questionable impact on ecological sustainability. In consequence, an undue emphasis on protecting not only polluting industries, businesses, and goods but also unsustainable institutions, values, and practices might follow simply because these marketing system elements are deemed key to societal (actually economic) welfare. The fear of losing economic welfare might hinder genuinely transformative policy initiatives that might get us closer to welfare marketing (Varey 2010). Instead, incremental reforms will be preferred under the assumption that society will gain progressively increasing magnitudes of (economic) welfare for the same amount of the lost natural capital. On the other hand, the findings have implications for which a policy that compensates for environmental harm is preferred. The trade-off conjecture enforces the belief that compensation payments for inflicted environmental harms restore the welfare of a locality. Conceptually, the conjecture leads to an interpretation of events as a monetary problem. In this case, the proper evaluation of the harm and setting the appropriate mechanisms of compensation is a challenge. In contrast, our findings suggest that only full restoration of the natural resources or, at least, major mitigation policies can restore the welfare balance. Hence, to maintain societal welfare, the lost natural capital should be replaced with the same one, not with an economic output of the marketing system.

\section{Study Limitations and Future Research}

The scope of the current study is limited to a single country. Because environmental entropy is increasingly becoming a global phenomenon (Stern 2007), interactions between countries might have been ignored. Moreover, marketing or consumption-related pollution might have been underestimated because pollution-intensive industries are being relocated to countries with cheap labor. For instance, the consumption of imported material goods is significant in the United States, while all the pollution relevant to these imports is not accounted for in our study.

Another limitation is the imperfect operationalization of the concepts. For example, the advertising expenditure time series might significantly underestimate the true magnitude of producer marketing activities. However, the choices made can be defended within the context of time-series analysis, where the absolute magnitude of the variable is less important than its evolution over time. What matters here is a change in the variable as it evolves over time, which might closely mimic the true expansion of the system. Similarly, consumption is diverse at the disaggregated level. It must be noted that some types of consumption are more ecologically consequential than others. Another concern might be the absence of the second cointegrating relationship (Hypothesis 3) in EWSECM contrary to what has been hypothesized. This can be interpreted as follows. From the neoclassical point of view, marketing is not responsible for environmental entropy in the long run. Consistent with Crane and Desmond (2002), the orthodox perspective views the role of marketing as purely technical, shifting the blame to consumer preferences and practices. Therefore, consumption, not the marketing system, has a positive significant impact on environmental entropy but only in the short run. Future research is necessary to test whether the conclusions would hold using an alternative set of improved measures or replicating the study in another country.

\section{Acknowledgment}

The author thanks the editor and two anonymous Journal of Macromarketing reviewers for their extremely helpful comments.

\section{Declaration of Conflicting Interests}

The author declared no potential conflicts of interest with respect to the research, authorship, and/or publication of this article.

\section{Funding}

The author received no financial support for the research, authorship, and/or publication of this article.

\section{References}

Ahuvia, Aaron C. and Douglas C. Friedman (1998), "Income, Consumption, and Subjective Well-Being: Toward a Composite Macromarketing Model," Journal of Macromarketing, 18 (2), 153-168.

Bartels, Robert (1970), Marketing Theory and Metatheory. Homewood, IL: R. D. Irwin.

Blanchflower, David G. and Andrew J. Oswald (2004), "Well-being Over Time in Britain and the USA," Journal of Public Economics, 88 (7-8), 1359-1386.

Box, George and Gwilym Jenkins (1976), Time Series Analysis, Forecasting, and Control. San Francisco, CA: Holden Day.

Brennan, Ross, Lynne Eagle, and David Rice (2010), "Medicalization and Marketing," Journal of Macromarketing, 30 (1), 8-22.

Broadbent, Simon (1979), "One Way TV Advertisements Work," Journal of the Market Research Society, 21 (3), 139-165.

Brown, Thomas C. and Robin Gregory (1999), "Why the WTA-WTP Disparity Matters," Ecological Economics, 28 (3), 323-335.

Cleveland, Cutler J. and Matthias Ruth (1997), "When, Where, and by How Much Do Biophysical Limits Constrain the Economic Process? A Survey of Nicholas Georgescu-Roegen's Contribution to Ecological Economics," Ecological Economics, 22 (3), 203-223.

Crane, Andrew (2000), "Marketing and the Natural Environment: What Role for Morality?" Journal of Macromarketing, 20 (2), 144-155.

and John Desmond (2002), "Societal Marketing and Morality," European Journal of Marketing, 36 (5/6), 548-569. 
Davies, Geoff (2004), Economia: New Economic Systems to Empower People and Support the Living World. Sydney, Australia: ABC Books.

Dawson, Michael (2003), The Consumer Trap: Big Business Marketing in American Life, The History of Communication. Urbana: University of Illinois Press.

De Graaf, John, David Wann, and Thomas H. Naylor (2005), Affluenza: The All-Consuming Epidemic. San Francisco, CA: Berrett-Koehler.

Dekimpe, Marnik G. and Dominique M. Hanssens (1995), "Empirical Generalizations about Market Evolution and Stationarity," Marketing Science, 14 (3), 109-121.

Dennis, Jonathan G., Henrick Hansen, Soren Johansen, and Katarina Juselius (2005), CATS in RATS 2 (Version 2). Evanston, IL: Estima.

Dowling, Grahame R. (1983), "The Application of General Systems Theory to an Analysis of Marketing Systems," Journal of Macromarketing, 3 (2), 22-32.

Durning, Alan T. (1992), How Much is Enough? The Consumer Society and the Future of the Earth. New York, NY: Norton.

Easterlin, Richard A. (1995), "Will Raising the Incomes of All Increase the Happiness of All?" Journal of Economic Behavior and Organization, 27 (1), 35-47.

Ferrer-i-Carbonell, Ada and John M. Gowdy (2007), “Environmental Degradation and Happiness," Ecological Economics, 60 (3), 509-516.

Fisher, Irving (1906), The Nature of Capital and Income. New York, NY: Macmillan.

Fisk, George (1974), Marketing and the Ecological Crisis. New York, NY: Harper \& Row.

Galbraith, John K. (1958), The Affluent Society. Harmondsworth, Middlesex: Penguin Books.

Georgescu-Roegen, Nicholas (1971), The Entropy Law and the Economic Process. Cambridge, MA: Harvard University Press.

Gowdy, John M. (2005), "Toward a New Welfare Economics for Sustainability," Ecological Economics, 53 (2), 211-222.

Hamilton, James D. (1994), Time Series Analysis. Princeton, NJ: Princeton University Press.

Hanssens, Dominique M., Leonard J. Parsons, and Randall L. Schultz (2001), Market Response Models: Econometric and Time Series Analysis. Norwell, MA: Kluwer Academic Publishers.

Hicks, John R. (1975), Value and Capital: An Inquiry into Some Fundamental Principles of Economic Theory. New York, NY: Oxford University Press.

Holbrook, Morris B. (1998), "The Dangers of Educational and Cultural Populism: Three Vignettes on the Problems of Aesthetic Insensitivity, the Pitfalls of Pandering, and the Virtues of Artistic Integrity," Journal of Consumer Affairs, 32 (2), 394-423.

Hunt, Shelby D. (1981), "Macromarketing as Multidimensional Concept," Journal of Macromarketing, 1 (1), 7-8.

Johansen, Soren J. (1995), Likelihood-based Inference in Cointegrated Vector Autoregressive Models. Oxford: Oxford University Press.

- and Katarina Juselius (1990), "Maximum Likelihood Estimation and Inference on Cointegration with Application to the Demand for Money," Oxford Bulletin of Economics and Statistics, 52 (2), 169-209.
Kilbourne, Willliam E. and Suzan Beckmann (1998), "Review and Critical Assessment of Research on Marketing and the Environment," Journal of Marketing Management, 14 (6), 513-533.

—-, Michael J. Dorsch, Pierre McDonagh, Bertr and Urien, Andrea Prothero, Marko Grunhagen, Michael Jay Polonsky, David Marshall, Janice Foley, and Alan Bradshaw (2009), "The Institutional Foundations of Materialism in Western Societies," Journal of Macromarketing, 29 (3), 259-278.

, Pierre McDonagh, and Andrea Prothero (1997), "Sustainable Consumption and the Quality of Life: A Macromarketing Challenge to the Dominant Social Paradigm," Journal of Macromarketing, 17 (1), 4-21.

Kotler, Philip and Sidney J. Levy (1973), "Buying is Marketing Too!” Journal of Marketing, 37 (1), 54-59.

Kuznets, Simon (1934), "National Income, 1929-1932," 73rd US Congress, $2 \mathrm{~d}$ session. Senate document no. 124, 7.

Lawn, Philip A. (2003), “A Theoretical Foundation to Support the Index of Sustainable Economic Welfare (ISEW), Genuine Progress Indicator (GPI), and Other Related Indexes," Ecological Economics, 44 (1), 105-118.

Layton, Roger A. (2007), "Marketing Systems-A Core Macromarketing Concept," Journal of Macromarketing, 27 (3), 227-242.

Lutkepohl, Helmut (1991), Introduction to Time Series Analysis. Berlin, Germany: Springer-Verlag.

Mittelstaedt, John D., William E. Kilbourne, and Robert A. Mittelstaedt (2006), "Macromarketing as Agorology: Macromarketing Theory and the Study of the Agora," Journal of Macromarketing, 26 (2), 131-142.

Nath, S. K. (1973), A Perspective of Welfare Economics. London, UK: The Macmillan Press.

Pan, Yue, George M. Zinkhan, and Shibin Sheng (2007), "The Subjective Well-Being of Nations: A Role for Marketing?" Journal of Macromarketing, 27 (4), 360-369.

Patterson, Kerry (2000), An Introduction to Applied Econometrics: A Time Series Approach. Houndmills, UK: Palgrave.

Pigou, Arthur C. (2002), The Economics of Welfare. New Brunswick, NJ: Transaction.

Rehdanz, Katrin and David Maddison (2008), “Local Environmental Quality and Life-Satisfaction in Germany," Ecological Economics, 64 (4), 787-797.

and (2005), "Climate and Happiness," Ecological Economics, 52 (1), 111-125.

Reidenbach, Eric R. and Terence A. Oliva (1983), "Toward a Theory of the Macro Systemic Effects of the Marketing Function," Journal of Macromarketing, 3 (2), 33-40.

- and (1981), "General Living Systems Theory and Marketing: A Framework for Analysis," Journal of Marketing, 45 (4), 30-37.

Schor, Juliet (1999), The Overspent American: Why We Want What We Don't Need. New York, NY: Harper Perennial.

Scitovsky, Tibor (1976), The Joyless Economy: The Psychology of Human Satisfaction. Oxford: Oxford University Press.

Sheth, Jagdish N. and Rajendra S. Sisodia (2006), Does Marketing Need Reform? Fresh Perspectives on the Future. Armonk, NY: M. E. Sharpe. 
and - (2005), "A Dangerous Divergence: Marketing and Society," Journal of Public Policy \& Marketing, 24 (1), 160-162.

Shultz, Clifford, J. and B. Morris Holbrook (1999), "Marketing and the Tragedy of the Commons: A Synthesis, Commentary, and Analysis for Action," Journal of Public Policy \& Marketing, 18 (2), 218-230.

Smith, Toby M. (1998), The Myth of Green Marketing: Tending Our Goats at the Edge of Apocalypse. Toronto, ON: Toronto University Press.

Spring, Joel H. (2003), Educating the Consumer-Citizen: A History of the Marriage of Schools, Advertising, and Media. Mahwah, NJ: Lawrence Erlbaum.

Stern, Nicholas (2007), The Economics of Climate Change: The Stern Review. Cambridge: Cambridge University Press.

Stockhammer, Engelbert, Harald Hochreiter, Bernhard Obermayr, and Klaus Steiner (1997), "The Index of Sustainable Economic Welfare (ISEW) as an Alternative to GDP in Measuring Economic Welfare. The Results of the Austrian (Revised) ISEW Calculation 1955-1992," Ecological Economics, 21 (1), 19-34.

Talberth, John and Alok K. Bohara (2006), "Economic Openness and Green GDP," Ecological Economics, 58 (4), 743-758.

, Clifford Cobb, and Noah Slattery (2007), The Genuine Progress Indicator 2006: A Tool for Sustainable Development. Oakland, CA: Redefining Progress.
Varey, Richard J. (2010), "Marketing Means and Ends for a Sustainable Society: A Welfare Agenda for Transformative Change," Journal of Macromarketing, 30 (2), 112-126.

Welsch, Heinz. (2006), "Environment and Happiness: Valuation of Air Pollution Using Life Satisfaction Data," Ecological Economics, 58 (4), 801-813.

(2002), "Preferences over Prosperity and Pollution: Environmental Valuation based on Happiness Surveys," Kyklos, 55 (4), 473-494.

Wilkie, William L. and Elizabeth S. Moore (1999), "Marketing's Contributions to Society," Journal of Marketing, 63 (4), 198-218.

\section{Bio}

Djavlonbek Kadirov is a senior lecturer at the School of Business at the Eastern Institute of Technology, Hawke's Bay, New Zealand. He received an MSc in Marketing from the University of Salford, UK, and a $\mathrm{PhD}$ in Marketing from the University of Waikato, New Zealand. His research interests include general macromarketing issues, sustainable marketing systems, marketing and society, meanings and (in)authenticity in consumer culture, and time-series modeling. His research appeared in the Journal of Macromarketing, Journal of Customer Behaviour, Journal of Research for Consumers, and the Journal of Place Management and Development. 